\title{
Moderating Effect of Cyber Bullying on the Psychological Well-Being of In-School Adolescents in Benin Edo State Nigeria
}

\author{
By Okoiye, O. Emmanuel ${ }^{1} \mathrm{PhD}$, Nwoga Anayochi . $\mathrm{N}^{1}$ \\ \& Onah, A. Thompson ${ }^{1}$
}

\begin{abstract}
This study adopted a descriptive survey research design of ex-post factor type to determine the moderating effect of cyber bullying on the psychological well-being of inschool adolescents in Benin Edo State Nigeria. Simple random sampling technique was used to select 300 in-school adolescents from fifteen randomly selected secondary schools in Benin Edo state. Four instruments used were: Cyber Bullying Prevalence Questionnaire (CBPQ) $(\alpha=0.84)$; Rosenberg's self-esteem scale (RSE) $(\alpha=0.88)$; Self-Concept Clarity Scale: $(\alpha=0.88)$ and General Self-Efficacy (GSE) scale $(\alpha=0.90)$. Two research questions were answered and three hypotheses tested at 0.05 level of significance. Data were analysed using Pearson Product Moment Correlation and Multiple Regression. The measures of association between the variables identified in the study revealed that there was significant relationship between the variables (self-esteem, self-concept, self-efficacy and cyber bullying). The study produced an F-Ratio $(3 / 296)=10.451$ which implies that the consequence of cyber bullying has impact on in-school adolescent's self-esteem, selfconcept and self-efficacy. Also, self-esteem correlate with cyber bullying of-in school adolescents, $\mathrm{r}(298)=.289, \mathrm{p}<.05$. Likewise, self-concept correlates significantly with cyber bullying of in-school adolescents, $\mathrm{r}(298)=.457, \mathrm{p}<.05$. Furthermore, self-efficacy correlate significantly with cyber bullying of in-school adolescents, $r(298)=.261, \mathrm{p}<.05$. Therefore, it is recommended that adolescents should be taught moral instructions in school as it would help them be of good character and develop the ability to negotiate relationships positively with significant other in the society.
\end{abstract}

Keywords: Adolescent, Cyber Bullying, Self-esteem, Self-concept, Self-efficacy, Benin and Nigeria.

\section{Introduction}

The incidence of bullying among in-school adolescents has taken a new dimension with the use of information communication technology device. The internet is a medium that is commonly used now by most in-school adolescent to perpetuate cyber bullying. This form of violence is manifested in the form of verbal threats, attacks and taunts from peers while chatting via the internet or text messages. This development 
is now gaining momentum in Nigeria with an unimaginable psychological effect on the well-being of in-school adolescents. According to Keith and Martin (2005) in this $21^{\text {st }}$ Century, school violence has taken on a new and more insidious form with the application of new technologies that have made it easier for bullies to gain access to their victims without physical contact.

This implies that advancement in modern technology has influenced a new method of victimization that has taken traditional bullying to a new extreme dimension. Cyber bullying, the voluntary and repetitious abuse that is inflicted through computers, cell phones, and other electronic devices (Hinduja \& Patchin, 2010), is a modern method of victimization that has affected over 40 percent of adolescents in the past year (National Crime Prevention Council, 2010). Similar to traditional bullying, cyber bullying is used to exert power and dominance over another person (Beran \& Li, 2005). Cyber bullying, however, accomplishes this control through text messaging, instant messaging, or social networking websites, such as Facebook, MySpace, and Twitter (Beran \& Li, 2005), enabling the cyber bully to harass, threaten, or ridicule the victim in both public (e.g., the internet) and private domains (e.g., text messaging) (Palmeri, 2013).

Also, Mesch (2009) posits that cyber bullying jeopardizes the mental, emotional, and physical well being of children and puts society at the risk of ethical and moral deterioration. Unlike face-to-face bullying it does not end from the time the school gets over but follows the child/adolescent back home with an easy access to the various forms of digital communication gadget. However, this form of bullying is recent because of the increase of mobile phones and internet usage within the adolescent population (Mesch, 2009).

Palmeri (2013) assert that cyber bullying is a unique component that can be especially detrimental for victimized adolescents. For example, a cyber bully victim can receive an unlimited amount of harassing messages through several different networks. Within a matter of minutes the cyber bully can post a rumour on a victim's Face book status or send harassing text messages that fill the victim's inbox. Each of these methods attribute to the inescapability of cyber bullying by broadening the potential audience of the cyber bully attack (Sourander, Brunstein-Klomek, Helenius, Ikonen, Lindroos, Luntamo \& Koskelainen, 2010). If a cyber bully posts something embarrassing or defaming about the victim on any social networking website, everyone who is a friend with the cyber bully or the victim has the potential to see the post. The victim not only has to deal with the embarrassment of being victimized, but also with the knowledge that everyone who has access to the Internet is able to witness this humiliation. Thus, cyber bullying can cause significant emotional and psychological harm that can result to affected in-school adolescents developing low self-esteem, poor self-concept and become less efficacious in their relationship with their environment (Sourander, et al, 2010).

Adolescence is a period of identity formation and a time they crave for social acceptance which when not attain mars the well-being of an adolescent. The social network media is a medium used by in-school adolescents to establish their identity and seek social recognition and peer acceptance via chatting or conferencing. However, if they experience cyber bullying, it impact negatively on their psychological and emotional wellbeing. In support, Beaty and Alexeyev (2008) state that victims of cyber bullying tend to have lower self-esteem than non-victims. It has also been found that repeated acts of 
cyber bullying has been shown to threaten healthy development of self-esteem in youths and contribute to school failure and dropout (Raskauskas \& Stoltz, 2007) and increase psychological symptoms such as depression and anxiety (Raskauskas \& Lynch, 2007).

The victim of cyber bullying has also been related to the development of general psychological distress and poor psychosocial adjustment such as the development of low self-concept (Raskauskas \& Stoltz, 2007). In a study involving victims of cyber-bullying, $31 \%$ of students victimized reported being very or extremely upset, $19 \%$ were very or extremely afraid, and18\% were very or extremely embarrassed by online harassment (Raskauskas \& Stoltz, 2007). Bullies' low self-perceptions may serve as a motivator for their engagement in bullying behaviours so as to enhance facets of their self-concept. As a consequence of their bullying behaviours, bullies may attain a personal perception of power and status in the social group which reinforces their behaviour (Parada, Marsh, Craven \& Papworth, 2005). When specific facets of self-concept have been considered, it has been found that those who are bullied tend to have negative self-perceptions with reference to the degree with which they view themselves as socially capable or accepted by their peers (Hawker \& Boulton, 2000).

Contemporary research as to the effects of cyber bullying indicates that victims of this phenomenon often experience symptoms such as depression, anxiety, loneliness, social exclusion, poor academic performance, and some experience suicidal thoughts (Juvonen \& Gross, 2008). Scientific research has found that these types of symptoms are determined by the level of self-efficacy a person has (Bandura, 1997). Victims with a low sense of self-efficacy believe that they cannot manage the potential threats associated with victimization, and they experience high levels of stress, anxiety, and depression (Bandura, 1997). Furthermore, adolescent victims with a low sense of self-efficacy tend not to dwell on their coping deficiencies and view many aspects of their environment as fraught with danger (Bandura, 1997). Likewise, Lazuras, Barkoukis and Tsorbatzoudis (2012) found that self-efficacy beliefs mediate the effects of empathy on cyber bullying intentions among Greek adolescents.

\section{Statement of the Problem}

Cyber bullying involves harassment or mistreatment carried out by an offender against a victim who is physically distant. Nonetheless, though cyber bullying does not involve personal contact between an offender and victim, it remains psychologically and emotionally damaging to youth. These development causes strain that elicit or produce feelings of anger, frustration, or depression - which then can surface as negative behavioural choices. Therefore, it could be said that in-school adolescents that experience strain in interpersonal relationship due to being bullied are more at risk to engage in deviant or delinquent behaviours. This implies that cyber bullying victimization can be a potent source of emotional and psychological strain among in-school adolescents that can in turn lead to deviant coping responses.

\subsection{Research Questions}

The following research questions were answered in the study: 
1. What relationships exist between in-school adolescent's self-esteem, selfconcept, self-efficacy and cyber bullying?

2. What impact does cyber bullying have on in-school adolescent's self-esteem, self-concept and self-efficacy?

\subsection{Research Hypotheses}

The following hypotheses are tested at 0.05 margin of error.

1. There is no significant relationship between self-esteem and cyber bullying of inschool adolescents?

2. There is no significant relationship between self-concept and cyber bullying of in-school adolescents?

3. There is no significant relationship between self-efficacy and cyber bullying of in-school adolescents?

\section{Methodology}

\subsection{Research design}

This study adopted a descriptive survey design of ex-post factor type.

\section{Population}

The population for this study consists of all in-school adolescents in Benin Metropolis in Edo State Nigeria.

\section{Sample and Sampling Technique}

Simple random sampling technique was used to select three hundred senior secondary in-school adolescents (SSSIII) comprising of male and female students from fifteen randomly selected secondary schools in Benin Edo State Nigeria.

\subsection{Instrumentation}

The Cyber Bullying Prevalence Questionnaire (CBPQ) by Rigby and Slee, (1999) was used to measure incidence of cyber bullying among in-school adolescents. It is a twenty item instrument that has being used across culture and proven to be reliable. It has items such as: I like to harass people on internet: I like to intimidate people I chat with on my social network etc. The instrument has a reliability coefficient of 0.84 .

Rosenberg's self-esteem scale (RSE) Self-esteem was measured using Rosenberg's self-esteem scale. This 10 -item self-report measure requires respondents to indicate their perceptions of themselves in positive or negative ways. Examples of items in the scale are: "I am able to do things as well as most other people do" and "I can do anything I really set my mind to". Learners respond on a 4 -point scale $(4=$ strongly agree, $3=$ agree, 2 = disagree and $1=$ strongly disagree) with higher total scores indicating a stronger self-esteem. The test-retest reliability of RSE ranged from 0.85 to 0.88 .

Self-Concept Clarity Scale (Campbell, Trapnell, Heine, Katz, Lavallee \& Lehman, 1996): This scale was used to measure the self-concept of in-school adolescents. It is a12-item measure of the degree to which individuals rate a clear notion of who they are. An example item is: "In general, I have a clear sense of who I am and what I am." The scale is a 4-point scale. Higher scores reflect higher self-concept clarity. The scale has an alpha reliability coefficient of 0.88 . 
General Self-Efficacy (GSE) scale by (Schwarzer \& Jerusalem, 1995) was used to measure in-school adolescent's self-efficacy. This scale is created to predict coping with daily hassles as well as adaptation after experiencing various kinds of stressful life events. It is a ten item standardized instrument that requires 10 minutes on average to answer the questions. Responses are made on a 4-point scale. Responses to all 10 items are summed up to yield the final composite score, with a range from 10 to 40 . No recoding. In samples from 23 nations, Cronbach's alphas ranged from .76 to .90. The scale is unidimensional, as found in a series of confirmatory factor analyses (Scholz, GutiérrezDoña, Sud, \& Schwarzer, 2002). Criterion related validity is documented in numerous correlation studies where positive coefficients were found with favourable emotions, dispositional optimism, and work satisfaction. Negative coefficients were found with depression, anxiety, stress, burnout, and health complaints.

\section{Procedure}

The researchers sought the consent of the principals, teachers and students of the schools to be used for the study and also explained the need for the study, after which the research questionnaires were personally administered to them and collected back for data analysis.

\section{Data analysis}

Data was analyzed using Pearson product moment correlation and multiple regression analysis statistical tools at 0.05 level of significance. Multiple regression was used to seek answer to the research questions asked and PPMC was used to determine if the level of relationship between the variables were statistically significant to warrant rejection or acceptance of the hypothesis.

\section{Results}

The results of the findings are thus, presented in the tables below:

Research question 1: What relationships exist between in-school adolescent's self-esteem, self-concept, self-efficacy and cyber bullying?

Table 1: Descriptive Statistics and Correlation Matrix of Relationship between in-school adolescent's self-esteem, self-concept, self-efficacy and cyber bullying

\begin{tabular}{|llllllll|}
\hline Variables & $\mathbf{N}$ & Mean & Std. Dev & $\mathbf{1}$ & $\mathbf{2}$ & $\mathbf{3}$ & $\mathbf{4}$ \\
Cyber Bullying & 300 & 49.83 & 10.26 & 1.000 & & & \\
Self-Esteem & 300 & 29.31 & 4.734 & .289 & 1.000 & & \\
Self-Concept & 300 & 47.25 & 9.131 & .457 & .078 & 1.000 & \\
Self-Efficacy & 300 & 40.88 & 7.637 & .261 & .105 & .077 & 1.000 \\
\hline
\end{tabular}

Table 1 gives description of measures of association between the variables identified in this study. The scores indicate that there is significant relationship between the variables (self-esteem, self-concept, self-efficacy and cyber bullying). One striking outcome of the inter-correlation results is that self-concept correlated most positively with cyber bullying of in-school-adolescents $(r=.457, \mathrm{p}<0.05)$. 
Research question 2: What impact does cyber bullying have on in-school adolescent's self-esteem, self-concept and self-efficacy?

Table 2: Regression summary table showing the impact of cyber bullying on in-school adolescents self-esteem, self-concept and self-efficacy

\begin{tabular}{|c|c|c|c|c|c|}
\hline $\begin{array}{l}\mathrm{R}=.371 \\
\mathrm{R}^{2=} .138 \\
\text { Adj } \mathrm{R}^{2=} .125 \\
\text { Std Error= } 9.5976 \\
\text { Source }\end{array}$ & Df & Sum squares (ss) & Mean square & F-Ratio & Sig \\
\hline Regression & 3 & 2887.981 & 962.660 & 10.451 & .000 \\
\hline Residual & 296 & 18054.239 & 92.113 & & \\
\hline Total & 299 & 20942.220 & & & \\
\hline
\end{tabular}

The result on table 2 revealed that the consequence of cyber bullying has impact on inschool adolescents self-esteem, self-concept and self-efficacy. This is revealed as thus, $\mathrm{R}=.371, \mathrm{R}^{2}=.138$, Adj. $\mathrm{R}^{2}=.125$ and Std. error of estimate 9.5976. The result of the multiple regression analysis produced an F-Ratio $(3 / 296)=10.451$ which was significant at $\mathrm{p}<0.05$ alpha level.

Hypothesis 1. There is no significant relationship between self-esteem and cyber bullying of in-school adolescents?

Table 3: PPMC summary table showing significant relationship between self-esteem and cyber bullying of in-school adolescents.

\begin{tabular}{|lllllll|}
\hline Variables & N & Mean & SD & R & Df & P \\
Cyber Bullying & 300 & 49.83 & 10.26 & .289 & 298 & Sig \\
Self-Esteem & 300 & 29.31 & 4.734 & & & \\
\hline
\end{tabular}

Table 3 shows that self-esteem correlate with the cyber bullying of-in school adolescents, $\mathrm{r}(298)=.289, \mathrm{p}<.05$. With this result the Ho: is thus rejected. This implies that the selfesteem of in-school adolescent's is impaired due to incidence of cyber bullying.

Hypothesis 2. There is no significant relationship between self-concept and cyber bullying of in-school adolescents.

Table 4: PPMC summary table showing significant relationship between self-concept and cyber bullying of in-school adolescents

\begin{tabular}{|lllllll|}
\hline Variables & N & Mean & SD & R & Df & P \\
Cyber Bullying & 300 & 49.83 & 10.26 & .457 & 298 & Sig \\
Self-Concept & 300 & 47.25 & 9.131 & & & \\
\hline
\end{tabular}

Table 4 shows that self-concept correlates significantly with cyber bullying of in-school adolescents, $\mathrm{r}(298)=.457, \mathrm{p}<.05$. With this result the Ho: is thus rejected. This implies that the cyber bullying impact greatly and negatively on the self-concept of in-school adolescents that experiences it. 
Hypothesis 3. There is no significant relationship between self-efficacy and cyber bullying of in-school adolescents

Table 5: PPMC summary table showing significant relationship between self-efficacy and cyber bullying of in-school adolescents

\begin{tabular}{|lllllll|}
\hline Variables & $\mathbf{N}$ & Mean & SD & R & Df & P \\
Cyber Bullying & 300 & 49.83 & 10.26 & .261 & 298 & Sig \\
Self-Efficacy & 300 & 40.88 & 7.6367 & & & \\
\hline
\end{tabular}

Table 5 shows that self-efficacy correlate significantly with cyber bullying of in-school adolescents, $\mathrm{r}(298)=.261, \mathrm{p}<.05$. With this result the Ho: is thus rejected. This implies that cyber bullying negatively affects the self-efficacy of in-school adolescents.

\section{Discussion of the findings}

Research Question One: What relationships exist between in-school adolescent's selfesteem, self-concept, self-efficacy and cyber bullying? The result of the study revealed that there is significant relationship between the variables (self-esteem, self-concept, selfefficacy and cyber bullying). This implies that the incidence of cyber bullying could make in-school adolescents develop low self-esteem, poor self-concept and become less selfefficacious in their relationship with their environment. This supports National Crime Prevention Council, (2010) report of the fact that cyber bullying is a modern method of victimization that has affected the psychological well-being of over 40 percent of adolescents in the past years.

Research Question Two: What impact does cyber bullying have on in-school adolescent's self-esteem, self-concept and self-efficacy? The findings of the study shows that cyber bullying has significant negative impact of the psychological well-being of inschool adolescents as indicated by the F-Ratio $(3 / 296)=10.451$ result of the study. The reason for this development could be that cyber bully as a form of violence is manifested in the form of verbal threats, attacks and taunts from peers while chatting via the internet or text messages and has gained momentum in Nigeria with an unimaginable psychological effect on the well-being of in-school adolescents. In congruence, Mesch (2009) posits that cyber bullying jeopardizes the mental, emotional, and physical well being of the children and puts society at the risk of ethical and moral deterioration. Unlike face-to-face bullying it does not end from the time the school gets over but follows the child/adolescent back home with an easy access to the various forms of digital communication.

Hypothesis 1. There is no significant relationship between self-esteem and cyber bullying of in-school adolescents? The result of the study shows that self-esteem correlate with the cyber bullying of-in school adolescents, $r(298)=.289, \mathrm{p}<.05$. This implies that the self-esteem of in-school adolescent's is impaired due to incidence of cyber bullying. This also highlights the fact that when in-school adolescents are bullied through the internet, face book or other social network media, they tend to have a 
depleted self-esteem considering the fact that other people in their social network would be aware of their experience(s). This corroborates Sourander, et al, (2010) report of the fact that if a cyber bully posts something embarrassing or defaming about the victim on any social networking website, everyone who is friends with the cyber bully or the victim has the potential to see the post. The victim not only has to deal with the embarrassment of being victimized, but also with the knowledge that everyone who has access to the Internet is able to witness this humiliation. Thus, cyber bullying can cause significant emotional and psychological harm that can result to affected in-school adolescents developing low self-esteem, poor self-concept and become less efficacious in their relationship with their environment (Sourander, et al, 2010).

Hypothesis 2. There is no significant relationship between self-concept and cyber bullying of in-school adolescents. The findings shows that self-concept correlates significantly with cyber bullying of in-school adolescents, $\mathrm{r}(298)=.457, \mathrm{p}<.05$. This indicates that cyber bullying impact greatly on the self-concept of in-school adolescents that experiences it. Thus, it is often observed that when in-school adolescents experience cyber bullying, they start having poor self-perception of themselves and consequently feel less appreciated by significant others and their experience may further mar their ability to develop positive identity. Thus, the victim of cyber bullying has also been related to the development of general psychological distress and poor psychosocial adjustment such as the development of low self-concept (Raskauskas \& Stoltz, 2007). In a study involving victims of cyber-bullying, $31 \%$ of students victimized reported being very or extremely upset, $19 \%$ were very or extremely afraid, and $18 \%$ were very or extremely embarrassed by online harassment. However, bullies' low self-perceptions may serve as a motivator for their engagement in bullying behaviours so as to enhance facets of their self-concept (Raskauskas \& Stoltz, 2007).

Hypothesis 3. There is no significant relationship between self-efficacy and cyber bullying of in-school adolescents. The findings of the study reveals that self-efficacy correlate significantly with cyber bullying of in-school adolescents, $r(298)=.261, \mathrm{p}<.05$. This implies that cyber bullying negatively affects the self-efficacy of in-school adolescents. This shows that when in-school adolescents consistently experience harassment and threat through cyber bullying, they tend to lose self-confidence and become less efficacious in their ability to face and overcome challenges that relates to negotiating relationships. Therefore, it is of note that victims with a low sense of selfefficacy believe that they cannot manage the potential threats associated with victimization, and they experience high levels of stress, anxiety, and depression (Bandura, 1997). Furthermore, adolescent victims with a low sense of self-efficacy "tend to dwell on their coping deficiencies and view many aspects of their environment as fraught with danger" (Bandura, 1997). Likewise, Lazuras, Barkoukis and Tsorbatzoudis (2012) found that self-efficacy beliefs mediated the effects of empathy on cyber bullying intentions among Greek adolescents. 


\section{Implication of findings}

The findings of this research provide reasonable information that can be applied in the field of counselling psychology, sociology and education to help in-school adolescent overcome their negative experience of cyber bullying. This implies that with appropriate attention focused on developmental life span of adolescents, parent and teachers should endeavour to develop good morals in adolescents as this would help them express good behavioural conduct in the society.

\section{Recommendations}

Adolescents should be given orientation on the need to develop good virtues, be disciplined and have positive self-control.

Parents should monitor their children use of internet by observing their discussion and antics.

Appropriate guidance should be given to adolescents as this will help them express good behavioural conduct in their interpersonal relationship with their peers.

Adolescents should be taught moral instructions in school as it would help them be of good character and potent the ability to negotiate relationships positively with other people in the society.

\section{Conclusion}

The incidence of bullying among in-school adolescents has taken a new dimension with the use of information communication technology device. The internet is a medium that is commonly used now by most in-school adolescent to perpetuate cyber bullying and these calls for urgent intervention.

\section{References}

Bandura, A. (1997). Self-efficacy: The Exercise of Control. New York: Freeman.

Beaty L. A, \& Alexeyev E. B. (2008). The problem of school bullies: what the research tells us. Adolescence;43(169):1-11.

Beran, T., \& Ling, Q. (2005). Cyber-harassment: A study of a new method for an old behavior. Journal of Educational Computing Research, 32(3), 265-277.

Campbell, J. D., Trapnell, P. D., Heine, S. J., Katz, I. M., Lavallee, L. F., \& Lehman, D. R. (1996). Selfconcept clarity: Measurement, personality correlates, and cultural boundaries. Journal of Personality and Social Psychology, 70(1), 141-156.

Hawker, D. S. J., \& Boulton, M. J. (2000). Twenty years research on peer victimization and psychosocial maladjustment: A meta-analytic review of cross-sectional studies. Journal of Child Psychology and Psychiatry, 41(4), 441-455.

Hinduja, S., \& Patchin, J. W. (2010). Bullying, cyberbullying, and suicide. Archives of Suicide Research, 14(3), 206-221.

Juvonen, J., \& Gross, E. (2008). Extending the School Grounds?-Bullying Experiences in Cyberspace. Journal of School Health, 78(9), 496-505.

Keith, S., \& Martin, M. (2005). Cyber-Bullying: Creating a culture of respect in a cyber world: Reclaiming Children \& Youth, 13(4), 224-228. 
Lazuras L. Barkoukis V \& Tsorbatzoudis H. (2012), Cyberbullying among Greek adolescents: Findings from a school based study. Paper presented at the conference on Cyberbullying in Adolescence, Bologna, 20 February.

Mesch, G. (2009). Parental mediation, online activities, and cyber bullying. Cyber Psychology \& Behaviour, 12(4), 387-393.

National Crime Prevention Council. (2010). Stop Cyberbullying Before it Starts Facts. Retrieved from http://www.ncpc.org/ resources/files/pdf/bullying/cyberbullying: Accessed on 3/04/2014.

Parada, R. H., Marsh, H. W., Craven, R. G., \& Papworth, B. A. (2005). Bullying in schools: What can we glean from self-concept theory? Paper presented at the Australian Association for Research in Education Conference, Parramatta, Australia.

Palmeri, J. M. (2013).“Cyberbullicide:” When Cyberbully Victims Can’t Escape: NYU Steinhardt - Applied Psychology

Raskauskas, J., \& Stoltz, A. D. (2007). Involvement in traditional and electronic bullying among adolescents. Developmental Psychology, 43, 564-575.

Rigby, K. \& Slee, P. T. (1999). Suicidal ideation among adolescent school children, involvement in bully victim problems and perceived low social support. Suicide and life- threatening behaviour. Vol. 29:119-30. In Rigby, K. (2003). Consequences of bullying in school. Canadian Journal of Psychiatry, $48,583-590$.

Rosenberg, M. (1965). Society and the adolescent self-image Princeton, NJ: Princeton University Press.

Schwarzer, R., \& Jerusalem, M. (1995). Generalized Self-Efficacy scale. In J. Weinman, S. Wright, \& M. Johnston (Eds.), Measures in health psychology: A user's portfolio. Causal and control beliefs (pp. 35-37). Windsor, UK: NFER-NELSON.

Sourander, A., Brunstein-Klomek, A., Helenius, H., Ikonen, M., Lindroos, J., Luntamo, T., \& Koskelainen, M. (2010). Psychosocial risk factors associated with cyberbullying among adolescents: A population-based study. Archives of General Psychiatry, 67(7), 720-728. 